\title{
AC 2009-747: FACING THE INFORMATION FLOOD WITH TABLET PCS
}

\section{Sabina Jeschke, University of Stuttgart}

After receiving her M.Sc. in Physics at the Berlin University of Technology in 1997, graduating with distinction, Sabina Jeschke worked as an assistant teacher at the department for mathematics and natural sciences and earned her doctorate in 2004. Holding a scholarship from the German National Academic Foundation, she spent several months of research at the NASA in Moffet Field, CA. In 2000 and 2001, S. Jeschke worked as an instructor at the GaTech (Georgia Institute of Technology, Atlanta). Since 2005, Sabina Jeschke has been associate professor for "New Media in Mathematics and Natural Sciences" and director of the MuLF Center (Multimedia Center for "New Media in Education and Research") at Berlin University of Technology (TU Berlin). Starting in 2001, her Berlin group has been a driving force behind the development of multimedia technologies at the university, implementing multimedia educational elements in the education of undergraduate students, in particular for engineering students. In May 2007, Sabina Jeschke has taken over a full professorship for "Information Technology Services" at the University of Stuttgart and is also acting as scientific and executive director (CEO) of the "Center of Information Technologies" of the University of Stuttgart. Additionally, she holds a co-professorship at the TU Berlin, in particular targeted towards the co-ordination of the design of new curricula in technology-oriented studies and the coordination of several eLearning and eResearch projects.

Contact Information:

University of Stuttgart Rechenzentrum Prof. Dr. Sabina Jeschke Allmandring 30a 70550 Stuttgart

Mail: sabina.jeschke@rus.uni-stuttgart.de Phone: +49-711-685-88000 Fax: +49-711-685-55898 WWW: http://www.rus.uni-stuttgart.de

\section{Lars Knipping, Technische Universitaet Berlin}

Lars Knipping is a researcher at the mathematics department at Technische Universität Berlin. He belongs to the board of editors of ITSE (International Journal of Interactive Technology and Smart Education) and the editorial team of iJET (International Journal of Emerging Technologies in Learning). He is a member of the DIN-NIA 36 expert group that cooperates with ISO SC-36 in creating e-learning standards (among them ISO/IEC 19796). Before joining Technische Universität he worked as a scientific consultant in a research project for a state-funded TV broadcaster, the "Sender Freies Berlin", followed by positions as researcher and instructor at the multimedia group at the computer science department of Freie Universität Berlin and as lecturer in International Media and Computing at the FHTW Berlin. Dr. Knipping received his Ph.D. degree for his work on the E-Chalk system and holds M.Sc. degrees in both mathematics and computer science.

Contact Information:

Technische Universität Berlin Medienzentrum für Lehre und Forschung Sekretariat MA 7-2 Dr. Lars Knipping

Mail: knipping@math.tu-berlin.de Phone:+49/(0)30/314 29782 Fax:+49/(0)30/314 24413

WWW: http://www.math.tu-berlin.de/ knipping

\section{Nicole Natho, Technische Universitaet Berlin}

Nicole Natho - Short CV

Dr. Nicole Natho received her M. Sc. in Physics at the Berlin University of Technology in 1998. Her thesis in theoretical physics investigated "Quantized Dirac-Fields on Kaluza-Klein Time-Space-Continua”. Subsequently she studied specialized pedagogic as applied to the fields of 
mathematics and physics and participated in the research and development of "interactive screen experiments" within the didactical group of the physics department at the TU Berlin. In the course of these studies she co-authored a paper on the deployment and advantages of interactive screen experiments in correspondence courses. During her postgraduate studies, Nicole Natho joined the Mumie project in 2001 where she developed authoring and computer-based content retrieval tools based on semantic encoding for the multimedia-platform Mumie. She received her $\mathrm{Ph}$.D. in mathematics for her thesis on the semantic analysis of mathematical language as applied to computer-based data retrieval in 2005. She is now part of the Team of the MuLF-Centre (Multimedia Centre for eLearning, eTeaching \& eResearch at the TU Berlin). Her research is focused on knowledge management systems and web engineering methods like semantic web and rich internet applications, especially problems of content-retrieval based on semantic encoding of natural language texts. Nicole Natho specializes in knowledge management mechanisms to extract information from mathematical texts with natural language processing methods and their corresponding semantic analysis and encoding. In this field, she is researching ontologies of mathematical language, their machine-processable representation, ontology mapping methods and methods of human-processable representations of ontologies in web interfaces.

Contact Information:

Technische Universität Berlin Medienzentrum für Lehre und Forschung Sekretariat MA 7-2 Dr. Nicole Natho

Mail: natho@math.tu-berlin.de Phone: +49/(0)30/314 79155 Fax: +49/(0)30/314 24413 WWW: http://www.math.tu-berlin.de/ natho

\section{Erhard Zorn, Technische Universitaet Berlin}

Erhard Zorn studies Physics and Mathematics at the Berlin Institute of Technology. After receiving his Dipom in Physics from the Berlin Institute of Technology he worked as a teaching assistant at the School of Mathematics and Natural Sciences. He spent the academic year 2000/01 at the Georgia Institute of Technology, Atlanta. Starting in 2001 he worked as a project manager and lecturerer at the Berlin Institute of Technology where he ist concerned with the mathematical education of engineers and physicists.

Contact Information:

Technische Universität Berlin Medienzentrum für Lehre und Forschung Sekretariat MA 7-2 Erhard Zorn

Mail: erhard@math.tu-berlin.de Phone: +49/(0)30/314 23646 Fax: +49/(0)30/314 24413

\section{Olivier Pfeiffer, Technische Universitaet Berlin}




\title{
Facing the information flood with Tablet PCs
}

\begin{abstract}
We present the application OneNote by the use of Tablet PCs in a sophomore lecture at Technische Universität Berlin, aimed at teaching students how to cooperate in their project-work using a collaborative platform. The implementation is described and a first evaluation is presented. Finally, a highly desirable extension for integrating mathematical notation is outlined.
\end{abstract}

\section{Introduction}

Information flood is an essential aspect of the digital age ${ }^{1,2,3}$. Consequently, organizing information of a specific subject efficiently without losing the overview is difficult. In education and especially in academic education, information management is a sensitive topic for freshmen and sophomores. Many students are overburdened with the new situation at university having to organize and manage all the new knowledge getting from lectures. The use of new media by lecturers and students provides an opportunity to overcome these challenges. Unfortunately, many of appropriate software applications need a lot of training time. In addition, lecturers cannot spend endless time to prepare a perfectly computerized course induced by the complexity of these software applications. What can we do for both parties?

Focusing on the social skills like communication, coordination and cooperation as nowadays' important factors in education, collaborative software applications possess a high potential to support the learning, teaching and research processes at university by the means of the new media and new technologies ${ }^{4,5}$. As a part of the GALILEA project, introduced at the Technische Universität Berlin, the new gender sensitive Bachelor of Science program "Natural Sciences in the Information Society" ${ }^{2,8}$ provides two new innovative lectures, which started in winter term 07/08 and summer term 2008, respectively:

1. Scientific Information Management (freshmen lecture) and

2. New Media in Education and Research (sophomore lecture)

This innovative program is designed to be very interdisciplinary while offering a broad spectrum of lectures in natural sciences, mathematics and computer science to a manageable student group of about 30 persons. The lectures "Scientific Information Management" and "New Media in Education and Research" were tailored to complete this program, are part of the compulsory lectures, and are perfectly suited to introduce concepts of Information Management using Tablet PCs in education.

To overcome the above described challenges, we use the collaborative platform Microsoft OneNote $2007^{9,10}$ (c.f. figure 1 for a screenshot) in the lecture "New Media in Education and Research" as a software application especially for Blended Learning Scenarios. One Note is a digital notepad with the flexibility of a classical handwritten notepad. Because of its affinity to other well-known office products, it is easy to use after a short training period. The use of OneNote in this context is based on the fundamental assumption that nearly everybody knows 
how to use office applications. Respectively, this collaborative platform offers the possibility to integrate with several office products. All notes are freely placeable and can be archived by different methods such as tagging or sorting by usefulness. Starting other applications and recording talks or small videos (podcasts) within this digital notepad is also possible. Internet resources can also be attached and tagged to notes. Besides, OneNote supports mobile devices as Tablet PCs, PDAs, and graphics tablets for handwritten notes. Briefly, the benefits of this application are its clarity, usability, and the opportunity to convey soft skills.

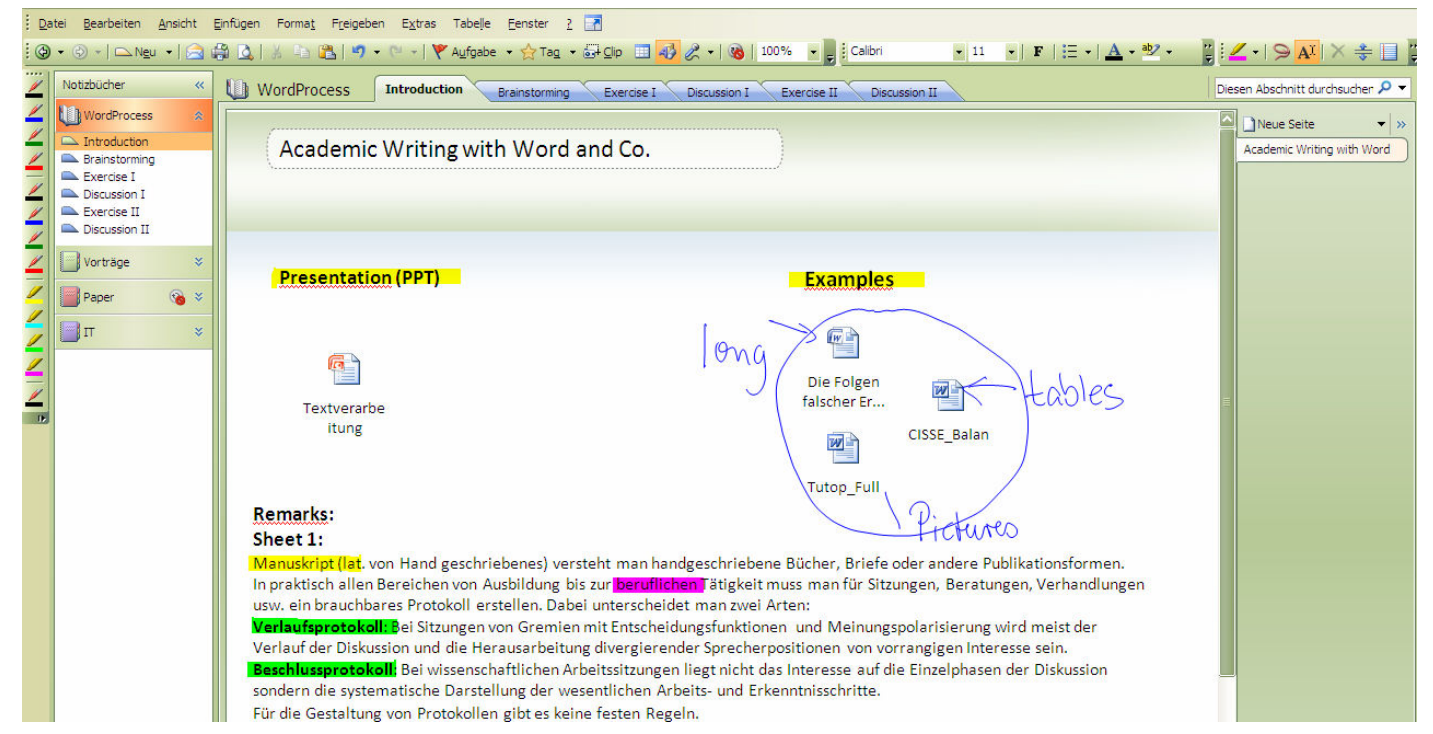

Figure 1. Microsoft OneNote 2007 screenshot.

In the following chapters, we present the preliminary results of our first evaluation. In line with the evaluation, the second chapter describes the theoretical and practical settings of this project in detail, and the comments of the students. Moving on, the third chapter reviews the drawbacks of the use of OneNote against the background of natural sciences and mathematics.

\section{Concept}

The lecture "New Media in Education and Research" covers the use of IT-Technologies in the fields of scientific communication, collaboration, teaching presentation and publication as well as for data acquisition in research. In the beginning, basics of New Media were treated by discussing digital representation of graphics, audio, video and textual data. Similarities and differences of the most popular desktop operating systems (Windows, Linux and OS X) and network basics were additional technical topics handled. The course introduced its students to typographic and design aspects of printed and electronic material. Communication models for use in presentations were outlined. Each participant trained his or her presentation skill by giving short scientific talks.

The lecture "New Media in Education and Research" is organized as an integrated lecture; i.e. it consists of frontal lectures by the teacher and project work, accomplished by the students in groups. Several projects are currently set up and carried out by the students using Tablet PCs and OneNote. The students gathered experiences with Office programs as well as with LATEX. They 
designed and created scientific flyers and posters and analyzed the structure of scientific articles. Online-Journals and Wikis were covered as alternative methods of publication. E-learning platforms, social networks and VoIP served as communication tool examples. Revision control system and shared applications were examined. The learners got hands-on-experiences with collaborative tools like MS OneNote 2007. Finally, data acquisition using databases, computer algebra systems and virtual laboratories was practiced and visualization and critical interpretation of statistical data were discussed.

\section{Blended Learning in Higher Education}

Blended learning is a model of education, combining traditional didactical methodologies with new media technologies for the presentation and distribution of knowledge. Therefore, this method unites the flexibility and efficiency of the new media with social components such as face-to-face communication, which is an important factor in modern higher education ${ }^{11,12,13,14}$. Done right, blended learning ensures the quality of the academic curriculum ${ }^{15,16,17,18}$. Moreover, from a psychological point of view blended education brings together different kind of didactical theories such as constructivism, behaviorism, and cognitivism ${ }^{11,19}$ to support different types of learners in their individual learning process ${ }^{20}$.

However, the main educational presentation for imparting basic knowledge about a field of study is still a lecture. In addition, faculty can concentrate on special topics in tutorials and seminars. However, in all models of educational styles, it is obviously complicated to integrate new media concepts into the curriculum, and additionally difficult to handle. In Germany, the deployment of new media is being promoted since 2000 to augment the professional use of new media for teaching, learning and examinations, yet the outcome of the actual use is sparse ${ }^{21,22}$. Of course, many lecturers have attempted to integrate new media in a blended learning approach, but they conclude that the relevant drawbacks are: the support to choose of all appropriate software applications and hardware products, the missing didactical concepts, and time-consuming integration into the curriculum. In this way, the advantages for lecturer to improve educational content are not apparently comprehensible. As a consequence the lecturers' motivation to use new media is decreasing especially during the initial implementation and in maintenance $^{23,24,25,26,30}$. In conclusion, everybody is aware that the new media requires substantial financial investments and personnel expenditure ${ }^{23}$. Additionally, for a successful introduction of the new media, four different types of lecturers, regarding their character attributes such as motivation, unstableness, readiness to assume risk for innovations respectively their willingness and ability, have to be considered. These four types: entrepreneurs, risk aversive, careerists, and reluctant, defined by Hagner ${ }^{27,28,25}$, have to be motivated each in a different way. Entrepreneurs are easy to manage because they are motivated primarily intrinsically using all offers on their own initiative. All other types need external motivation and they must be supported in technical and organizational matters. As a result, a sustainable implementation of new media within the higher education depends on miscellaneous factors, and the complexity of most of the educational innovations obfuscates the positive properties and $\operatorname{advantages}^{24,27}$.

Although individual support for Blended Learning means an additional workload, it appears as the most effective way to encourage lecturers and to implement E-education applications ${ }^{24}$. 


\section{Blended Learning Scenario with OneNote in Higher Education}

Which methodologies can be applied in higher education to develop practical expertise by the lectures for Blended Learning? According to ${ }^{26}$ the following fundamental requirements have to be provided and adapted to the target audience defined by Hagner $^{28}$ : development of quality especially for educational scenarios, advisory support, and augmentation of the lecturers' readiness.

One of the most significant issues is the lecturer's ability to conceive the didactical additional benefit being in opposition with the disadvantages and challenges such as time pressure, complexity of the implementation and missing support. To intercept these primary problems it is advisable to combine one specific didactical methodology with specific communication or information technology to systematize benefits between traditional didactical methodologies and new media concepts.

In this investigation, we focus on one specific information technology (office software products) combined with traditional didactical methodologies such as explorative or cooperative learning in classroom scenarios. The deployment of OneNote and akin applications ${ }^{29}$ can help resolve some challenges in altering the daily routine within Blended Learning scenarios: the lecturer is able to prepare the lecture directly on the computer similar to traditional preliminary techniques with an integration and execution of different applications and Internet resources. Additionally, media types like pictures, diagrams, notes, audio recordings, etc can be easily collected centrally by OneNote, whilst other content from web pages can be integrated by means of drag and drop. This information can be simply interchanged and shared between the individuals involved and between different teams. Particularly, OneNote supports the integration of inked sketches and comments, which are of great importance for the individual learning process especially in scientific education, and their usage is facilitated by Tablet PCs. In this way, OneNote acts like a control center for all relevant applications. During the lectures, students can be interactively integrated into the workflow in different ways such as explorative learning. The students and lecturers can collect and organize all these information types according to their personal preferences and requirements. However, the technical requirements for such lectures are a drawback.

\section{OneNote in Higher Education:}

\section{Exemplary Deployment}

An exemplary scenario is the use of OneNote as virtual whiteboard and collaborative environment during a course: the lecturer can centrally store every information in the application, presented to the audience by a projector and easily transfer them to the students' applications or vice versa. In this way, students and lecturer can share and transfer information and data without any difficulties. Within the context of the lecture "New Media in Education and Research" we 
have deployed OneNote in several educational units of this course. One educational unit is specified exemplary:

16 students attended the program "Natural Sciences in the Information Society"; about half of them were female students. During the lecture, the students worked in groups of two on Tablet PCs (HP Compaq tc4200, provided as part of a HP Technology for Teaching Grant). The subject of the teaching unit was "Academic Writing with Microsoft Word and Co" with the ambitious aim to work out the subject together with the students. The lecturer prepared the lecture with OneNote by creating a new digital notepad for managing all content i.e. examples, brainstorming notes, presentations, exercises, etc. with the Tablet PC facilitating the use of handwritten notes. The resulting exemplary 90 minutes lecture had following modules:

1. Introduction to "Academic writing in MS Word and Co" (duration: $20 \mathrm{~min}$ ): brief introduction to common problems of word processing applications in academic documents such as large documents, implementation of figures, images and tables, and the infamous footnotes.

2. Teamwork session "Explorative Examples" (duration: $20 \mathrm{~min}$ ): students work on some sophisticated examples with the aid of a digital worksheet.

3. Discussion of the results (duration $10 \mathrm{~min}$ ): exchange of information

4. Teamwork session: "Students' Examples" (duration $30 \mathrm{~min}$ ): working student examples on selected problems

5. Discussion of results (duration $10 \mathrm{~min}$ )

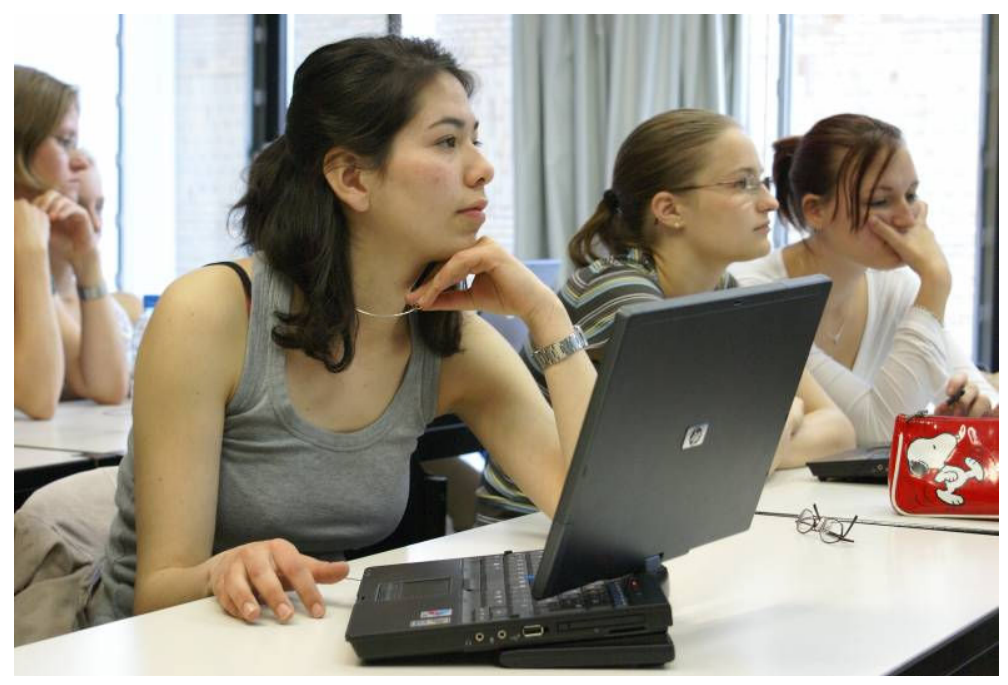

Figure 2: Students during a "New Media in Education and Research" lecture.

The first component of the educational unit is an introduction in form of a presentation about general problems of word processing programs with numerous examples. In most cases, there are several possible techniques to generate presentations and integrate them in OneNote; a PowerPoint presentation being on possibility, while another possibility is the use of OneNote as a digital board for making handwritten notes similar to a traditional lecture. Sharing this digital notepad with other participants, the students also have the possibility to add notes in this notepad. In addition, various examples can be directly executed in OneNote. For the second and 
fourth component of the lecture, the lecturer prepared possible exercises (digital worksheets) and attached programs, useful to study. The students also take their own notes in these segments. As the result for components three and five, the students shared their results with the lecturer and other students for discussion purposes. Moreover, the students were able to attach additional examples, or recorded comments. Accordingly, neither the teacher nor the students had "rough papers", and everything was arranged within the digital notepad (digitalized lecture). Finally, all integrated examples could be transferred to the students' notebooks.

\section{Extending the Concept to Mathematics and Natural Sciences}

When trying to apply the aforementioned techniques to a mathematics lecture we ask too much from the current release of OneNote, as complex formula, sets of symbols, and many technical illustrations need still need to be integrated into the application to make it valuable for mathematic or natural scientific lectures. Thus, the next version of OneNote needs to be extended to handle these particularities. Although OneNote already offers the possibility of exporting handwritten notes, making them available to other office-applications our goal is supporting the recognition of handwritten formula ${ }^{5}$, which shall then be evaluated by the prevalent mathematical tools: Maple, Matlab, and Mathematica. Additionally it is desirable to integrate a conversion tool to export technical outlines to a vector graphic application.

\section{Conclusion and Outlook}

The combination of Tablet PCs and OneNote is used to train students in cooperating in a collaborative information platform. The future integration of handwritten scientific content in OneNote is the next desirable future feature in this context.

Our preliminary results show that students perceive a lecture with OneNote as very fascinating, because of the variety of educational methodologies and differences to traditional lectures. Didactical concepts appear to be more similar to school education than to higher education at university. Working with digital examples implies spending more time to impart knowledge. A traditional lecture, as a non-invasive form of the Nuremberg Funnel, is designed to provide students with as much knowledge as possible in the available time. Consequently, the developed concepts are appropriate for selected lectures or seminars and tutorials. An additional challenge emerges from the technical overhead and costs to use notebooks or Tablet PCs, and applications such as OneNote. Yet, Blended Learning scenarios accelerate the progress of educational success in excess of traditional lectures due to the fact of large-scale integration of examples and interactivity. In conclusion, it remains to be examined whether Blended Learning scenarios with OneNote are acceptable and helpful for the lecturers with only sparse technical affinities in the sense of Hagner's ${ }^{28}$ four types.

It is worth recalling that the benefits of blended learning lectures with OneNote are obvious: lecturers prepare lectures or conduct handwritten lectures on the computer similar to traditional lectures. In summary, after a short training period it can be deployed straightforward because of its affinity to other well-known office applications, based on the fundamental idea that lecturers frequently use these applications. As a collaborative tool, it allows for the interactive integration of students into lectures, and it is an attractive alternative to a traditional lecture. 
At that time, experienced difficulties arise in lectures of mathematics, engineering, and natural sciences caused by the complex notation and technical outlines. Therefore, it is desirable to integrate special add-ons for scientific notation and conversion tools for technical outlines into a vector graphic application.

\section{Bibliography}

1. Association of College and Research Libraries: Information Literacy Competency Standards for Higher Education, http://www.ala.org/ala/acrl/acrlstandards/standards.pdf

2. Francis Heylighen, 2005, Information Overload, Complexity and Information Overload in Society: Why increasing efficiency leads to decreasing control, (submitted to The Information Society), http://pespmc1.vub.ac.be/papers/info-overload.pdf

3. Randall Stross, Struggling to Evade the E-Mail Tsunami, New York Times (2008-04-20), http://www.nytimes.com/2008/04/20/technology/20digi.html? r $=3 \&$ oref=slogin\&oref=slogin\&oref=slogin

4. Jeschke, Sabina and Cikic, Sabine and Natho, Nicole and Ludwig, Nadine and Pfeiffer, Olivier and Sinha, Uwe (2007) Modularization and Integration of Virtual Experiments. In: Proceedings of the 1st International Conference on Interactive Computer Aided Blended Learning (ICBL) 2007. Kassel University Press. ISBN 978-3-89958-277-2

5. Jeschke, Sabina and Knipping, Lars and Pfeiffer, Olivier (2007) Potential of Teaching with Intelligent Digital Chalkboards: Recent developments of the eChalk System. In: Proceedings of the 2nd International Conference on Interactive Mobile and Computer Aided Learning (IMCL) 2007. Kassel University Press. ISBN 987-389958-276-5

6. Jeschke, Sabina and Natho, Nicole and Pfeiffer, Olivier and Schröder, Christian and Wilke, Leticia (2007) Challenge Diversity: New Curricula in Natural Sciences, Computer Science and Engineering. In: Proceedings of the Frontiers in Education 2007. IEEE Computer Society, Los Alamitos, CA. ISBN 1-4244-1084-3

7. Jeschke, Sabina and Elsner, Maria and Natho, Nicole and Pfeiffer, Olivier and Schröder, Christian (2007) Attractive Universities: New Curricula in Natural Sciences and Engineering. In: Proceedings of the Meeting the Growing Demand For Engineers and Their Educators 2010 - 2020 International Summit. IEEE Computer Society, Los Alamitos, CA.

8. Nina Dahlmann, Maria Elsner, Sabina Jeschke, Nicole Natho, Christian Schröder (2008), Gender Gap in Technological Disciplines: Societal causes and consequences, to appear in 2008 International Symposium on Technology and Society (ISTAS 2008), IEEE Computer Society, Los Alamitos, CA.

9. Microsoft OneNote Homepage: http://office.microsoft.com/de-de/onenote/default.aspx

10. Herzog, Dagmar and Koch, Nina and Peters, Jan (2008) Selbstorganisation mit Microsoft Office OneNote 2007, Microsoft Press Deutschland, ISBN 978-3-86645-805-5

11. Reinmann-Rothmeier, Gabi (2003) Didaktische Innovation durch Blended Learning: Leitlinien anhand eines Beispiels aus der Hochschule Bern, Huber Verlag, Bern, ISBN: 978-3456839523

12. Schweizer, Karin and Paechter, Manuela and Weidenmann, Bernd. (2003) Blended learning as a strategy to improve collaborative task performance, Journal of Educational Media, Special Issue on Blended Learning, 28 (2-3), 211-224.

13. Kerres, Michael (2002) Online- und Präsenzelemente in hybriden Lernarrangements kombinieren. in: Hohenstein, Andreas and Wilbers, Klaus. (eds.), "Handbuch E-Learning", Fachverlag Deutscher Wirtschaftsdienst, Köln

14. Kerres, Michael and de Witt, Claudia and Stratmann, Jörg (2002) E-Learning: Didaktische Konzepte für erfolgreiches Lernen, in: Schwuchow, Karlheinz and Guttmann, Joachim (Ed.): Jahrbuch Personalentwicklung und Weiterbildung, Neuwied

15. Thomas Reichlmayr, Enhancing the student project team experience with blended learning techniques, Frontiers in Education, 2005. FIE '05. Proceedings 35th Annual Conference, 19-22 Oct. 2005 Page(s):T4F - 611, DOI 10.1109/FIE.2005.1611982

16. Toshihiro Hayashi, Hiroyuki Tominaga, and Toshinori Yamasaki, Blended learning contents for university education, Information Technology Based Higher Education and Training, 2006. ITHET '06. 7th International Conference on, July 2006 Page(s):499 - 502, DOI 10.1109/ITHET.2006.339802 
17. Bob Simington, Blended Learning - Neither Shaken nor Stirred, Advanced Semiconductor Manufacturing Conference, 2006. ASMC 2006. The 17th Annual SEMI/IEEE May 22-24, 2006 Page(s):358 - 361 , DOI 10.1109/ASMC.2006.1638783

18. Hoic-Bozic, N.; Mornar, V.; Boticki, I., A Blended Learning Approach to Course Design and Implementation, Education, IEEE Transactions on : Accepted for future publication, Volume PP, Forthcoming, 2003 Page(s):1 - 12, DOI 10.1109/TE.2007.914945

19. Catherine Twomey Fosnot, Constructivism: A Psychological Theory of Learning, In C. Fosnot, (editor) Constructivism: Theory, Perspectives and Practice" New York: Teachers College Press, Columbia University, 1996, 8-33.

20. Larry McNutt, and Marie Brennan, Work in Progress - Learning Styles and elearning, what is the Connection?, Frontiers in Education, 2005. FIE '05. Proceedings 35th Annual Conference, 19-22 Oct. 2005 Page(s):F1H-27 F1H-31, DOI 10.1109/FIE.2005.1612037

21. Werner, Benita (2006) Status E-Learning an deutschen Hochschulen. Institut für Wissensmedien., http://www.e-teaching.org/projekt/fallstudien/Status_des_ELearning.pdf

22. Seufert, Sabine ; Back, Andrea.; Häusler, Martin, Berger Sonja (2001) E-Learning : Weiterbildung im Internet. SmartBooks Publishing AG, 2001.- ISBN 978-3908490531

23. Encarnacao José Luis, Guddat, Hannes, Schnaider, Michael (2002) Die Hochschule auf dem Weg in e-Learning Zeitalter, in Ulrike Bentlage, Peter Glotz, Ingrid Hamm, Johannes Hummel (ed.) E-Learning: Märkte, Geschäftsmodelle, Perspektiven, Bertelsmann-Stiftung, Gütersloh, p. 21 - 55

24. Euler, Dieter, Hasanbegovic Jasmina, Kerres, Michael, Seufert Sabine (2006) Handbuch der Kompetenzentwicklung für e-Learning Innovationen: Eine Handlungsorientierung für innovative Bildungsarbeit in der Hochschule, Huber, Bern.

25. Kolbe, Harald and Nikolopoulos, Alexander (2007) Sustainable Implementation of e-Learning Innovations into Large German Universities, in: Proceedings of the 6th European Conference on e-Learning (ECEL 2007). Copenhagen, Denmark

26. Hasanbegovic, Jasmina and Kerres, Michael (2006): Entwicklung von Massnahmenportfolios zur Vermittlung von eLehrkompetenz, In: Seiler Schiedt, E. and Kälin, S. and Sengstag C. (Hrsg.) E-Learning - Alltagstaugliche Innovation? Münster: Waxmann Verlag.

27. Owston, Ron (2006): Evaluation of a blended learning professional development program for middle-school mathematics and science teachers. San Francisco : AERA, 2006

28. Hagner, Paul R. (2001) Faculty Engagement and Support in the New Learning Environment, in Educause Leadership Strategies, Volume 5, Technology-Enhanced Teaching and Learning: Leading and Supporting the Transformation on Your Campus, (ed) Hagner, Paul R., Barone, Carole A., Jossey Bass, ISBN: 9780787950132, p. 1 -12 http://net.educause.edu/ir/library/pdf/ERM0052.pdf

29. Alfred C. Weaver, Does Classroom Presenter Software Change Learning Outcomes?, Frontiers in Education Conference, 36th Annual, Oct. 2006 Page(s):10 - 14, DOI 10.1109/FIE.2006.322393

30. Zwellweger Moser, Franziska, (2007) The Strategic Management of E-Learning Support: Findings from American Research Universities, Waxmann Verlag, ISBN: 978-3830917328 